September 2018

APEC RR18-07

What's in a Name? Branding Reclaimed Water

Sean F. Ellis ${ }^{1}$, Olyessa Savchenko ${ }^{1}$, Kent D. Messer ${ }^{1}$

University of Delaware, Department of Applied Economics and Statistics, University of Delaware ${ }^{1}$

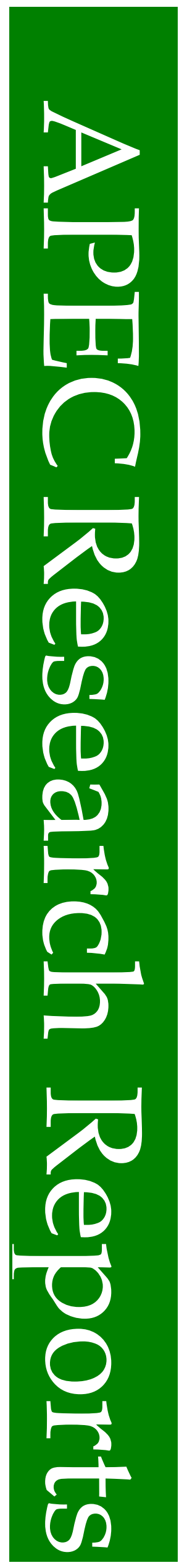




\title{
ABSTRACT \\ What's in a Name? Branding Reclaimed Water
}

Keywords: Reclaimed water; recycled water; reused water; food labeling; branding; drinking water; irrigation water

Reclaimed water is often presented as a cost-effective, reliable, and safe solution to increasingly common water shortages in the United States and across the globe, but studies have shown that consumers tend to object to the use of this water. Broad adoption of this technology will require consumer acceptance or at least tolerance of it, and studies have suggested that better branding could minimize or even overcome their concerns. This study uses an experimental approach to test consumer preferences for twenty-one potential branding names for reclaimed water and to determine whether an opportunity for consumers to try this water can change their preferences. The results suggest that the common names for this water, such as Recycled, Reclaimed, Nontraditional, Treated Wastewater, and Reused, are the least appealing, as they all scored at the bottom. In contrast, names that invoke desirable characteristics of the water-Pure, EcoFriendly, and Advanced Purified, were viewed significantly more favorable than the others. Having an opportunity to taste this water seems to clarify consumers' preferences by increasing the differences in favorability between the names. Based on these results, it appears that while there are a couple of appealing names, the most preferred is Pure Water.

\section{Acknowledgments}

Funding support for this research was provided by the U.S. Department of Agriculture's National Institute for Food and Agriculture and the Center for Behavioral and Experimental Agri-Environmental Research (CBEAR). The authors acknowledge the support of Julia Kesselring for assistance in preparing this manuscript and Natalie Brassill for obtaining potable reclaimed water.

\section{For Additional Information on this Research Course, please contact:}

\author{
Sean Ellis
}

Email: ellis@udel.edu

\section{Suggested Citation for APEC Research Report}

Ellis, Sean F., Savchenko, Olesya, Messer, Kent D., "What's in a Name? Branding Reclaimed Water" Applied Economics \& Statistics Research Report, University of Delaware, RR18-07. 


\section{What's in a Name? Branding Reclaimed Water}

"Pure water is the world's first and foremost medicine." -- Slovakian Proverb

\section{Introduction}

Reclaimed water is often presented as a cost-effective, reliable, and safe solution to increasingly common water shortages in the United States and around the world (Chen et al. 2013). However, numerous studies have shown that reclaimed water is often rejected by consumers (Menegaki, Hanley, and Tsagarakis 2007; Bakopoulou et al. 2008; Menegaki et al. 2009; Hui and Cain 2017; Ellis et al. 2017) because it invokes feelings of disgust (a “yuck” factor) related to wastewater, driving them to oppose its use (Fielding, Dolnicar, and Schultz 2018; Savchenko et al. 2018a). Several large-scale reclaimed water projects in the United States and Australia have been derailed by public resistance, making it difficult for policymakers to address water crises (Uhlmann and Head 2011; Morgan and Grant-Smith 2015; Hummer and Eden 2016). There is some evidence, though, that this negative public reaction could be minimized and perhaps, in some cases, eliminated through better branding of reclaimed water (Menegaki et al. 2009; Rock, Solop, and Gerrity 2012; Lee and Tan 2016). Widespread adoption of reclaimed water, which is critical for meeting the world's water needs in the future, depends on consumers accepting it. Thus, it is critical for policymakers and food and agricultural industries to understand how various types of branding of reclaimed water can mitigate the negative reaction associated with it. Using a large data set collected in two field studies involving 1,212 adult participants from the Mid-Atlantic region of the United States, this paper ${ }^{3}$ examines consumers' perceptions of a set of

\footnotetext{
${ }^{3}$ Funding for this study is part of larger efforts of the CONSERVE project (a Center of Excellence designated by the U.S. Department of Agriculture at the nexus of sustainable water reuse, food, and health) to fund research investigating consumer perceptions of the use of reclaimed water in agricultural production.
} 
potential brand names for reclaimed drinking water. To our knowledge, this is the first study to test consumers’ responses to branding names for reclaimed water using an experimental approach and to investigate whether having an opportunity to taste reclaimed water affects consumers’ preferences for the names.

Our study design involves two steps. First, we compare consumers’ preferences for twenty-one potential brand names for reclaimed water using survey responses from 305 adult respondents to identify the top six most-favored names. Then, in a second study involving 907 adult participants, we compare consumers' responses to the top six names selected from the previous study and examine the effect of having an opportunity to taste a treated and safe version of reclaimed water ${ }^{4}$ on consumer perceptions of the names. Prior studies have tested only a few brand names used interchangeably by scientists, agricultural producers, and water utilities (Menegaki et al. 2009; Rock, Solop, and Gerrity 2012); we test those brand names plus names currently being used to market reclaimed drinking water to consumers, names suggested by leading researchers in the field, and variations of names commonly found on food labels—-the most exhaustive analysis of brand names for reclaimed water to date.

\subsection{Background}

Worldwide, more than four billion people suffer from water shortages in at least one month per year and $40 \%$ of the U.S. population is affected by insufficient water supplies annually (Mekonnen and Hoekstra 2016). These shortages hit agricultural sectors particularly hard since agricultural production consumes 70\% of the global fresh water supply (World Water

\footnotetext{
${ }^{4}$ The potable reclaimed water was obtained from the Prima County Regional Wastewater Reclamation Department in Tuscon, Arizona through collaborators on the CONSERVE project.
} 
Assessment Programme 2016) and as much as 90\% of supplies in most western U.S. states (U.S. Department of Agriculture (USDA) Economic Research Service (ERS) 2017). Demand for fresh water is increasing because of population growth and economic development, which are expected to lead to a doubling of agricultural production by 2050. Meanwhile, existing fresh water supplies are dwindling because of over-use and shifts in precipitation and temperature related to climate change (World Bank 2014). New sources of water are desperately needed.

Reclaimed water-wastewater that is treated to meet state-specific standards to make it safe to use for potable and non-potable needs—-has proven to be a cost-effective, reliable, and safe solution to inadequate water supplies on a large scale in Israel, Singapore, and Australia and on a much smaller scale in the United States (Chen et al. 2013; Dery et al. 2018; WateReuse 2018). However, when consumers become aware that reclaimed water has been or will be added to their drinking water or used to irrigate the produce they buy, they typically either require a significant reduction in price to purchase and consume such products or they outright reject them (Menegaki, Hanley, and Tsagarakis 2007; Bakopoulou et al. 2008; Menegaki et al. 2009; Morgan and Grant-Smith 2015; Hui and Cain 2017; Ellis et al. 2017; Savchenko et al. 2018b). This overreaction to the potential risk associated with consuming reclaimed water, stems from the "toilet to tap" perception.

Several studies have shown that stigma attached to water “contaminated” by municipal waste, lead, or sterilized cockroaches was reduced or overcome by making consumers aware of the number of barriers between the water they consume and the source of the contagion (Rozin et al. 2015; Kecinski et al 2016; Hui and Cain 2017; Kecinski and Messer 2017). Showing or even just telling consumers that the water had been filtered reduced their stigmatization of it. Introducing intermediate steps such as putting treated wastewater into a surface body of water for 
a period of time or using it to recharge an aquifer before sending it to consumers' taps had the same effect (Rozin et al. 2015; Hui and Cain 2017). These processes seem to be perceived by consumers as having returned the water to a more natural, fresh, or pure state.

Companies that produce bottled drinking water have tended to emphasize the waters' natural state, freshness, and purity to market it. Most brands reference places of origin, such as glaciers, springs, and islands, to maintain the connection between the water and a natural, fresh source, even though several brands are simply filtered tap water (Wilk 2006; Hawkins 2009). Consumers often are not aware of the true source of the water because of relaxed regulations regarding food labeling and perceive bottled water as purer, safer, and healthier than tap water, which is not necessarily the case (Wanctin, Dalmeny, and Longfield 2006; Clarke 2007; Hawkins 2009; Hu, Morton and Mahler 2011). Even consumer claims that they can taste the difference between bottled and tap water have proven unreliable in blind taste tests (Wilk 2006). Still, producers of bottled water continue to promote their products as healthier by advertising that they naturally contain nutritious minerals or promote the water as "purified" because something has been removed from it (Wilk 2006; Hawkins 2009; Smith 2013).

Portraying a product as more natural and healthier than competing products is a common marketing tactic by the food industry. As consumers seek greater transparency in how foods are made, producers are responding with "clean-labeling”, a trend in which product ingredients are worded to appear natural and easily understandable (Aschemann-Witzel, Varela, and Peschel 2018). Some clean-labeled foods are new products, but others have simply had an ingredient removed or replaced and their label information rephrased (Katz and Williams 2011). Consider, for example, foods labeled as certified organic and "free from" ingredients such as preservatives. Consumers tend to view these products as more natural, healthy, and friendlier to the 
environment than alternatives such as genetically modified (GMO) foods and additives such as the synthetically produced growth hormone rBST even though there is no scientific proof of such benefits (Kanter et al, 2009; Lusk, Schroeder, and Tonsor 2014; Messer, Costanigro, and Kaiser 2017; Asioli et al. 2017). Likewise, for locally grown food. Consumers may view it as better for the environment, however, local production can require greater amounts of energy-intensive greenhouses or fertilizer inputs and thus be worse for the environment than growing the same food elsewhere and transporting it long distances (Costanigro, Deselnicu, and Kroll 2015).

Certain foods, such as prunes and rapeseed oil, have used rebranding to change their marketing trajectory and shed their undesirable associations, becoming dried plums and canola oil, respectively. Other products, like lean finely textured beef (LFTB), used a technical industry name because it was not actively marketed to the public, allowing it to be monikered "pink slime” when its presence in food was brought to the public's attention by news reports (Greene 2012). The term pink slime elicited the meat's "yuck" factor and suggested to consumers that it posed a food safety risk, causing the price of LFTB to plunge $42 \%$ between March and April 2012 (Detre and Gunderson 2012; Greene 2012; McKendree, Widmar, and Widmar 2014).

Currently, most references to reclaimed water use scientific and industry terms such as reused, reclaimed, recycled, and treated wastewater interchangeably because little research has been done on how best to market reclaimed water to the public. Studies have examined consumers' preferences for these terms and found that terms emphasizing the treatment processes the water went through were more effective than ones that focused on the wastewater source. Menegaki et al. (2009), for example, found that Greek consumers preferred the term recycled water to treated wastewater. Rock, Solop, and Gerrity (2012) found that consumers in 
Arizona responded more positively to water reuse, recycled water, repurified water, and reclaimed water than to effluent, tertiary treated wastewater, and toilet-to-tap.

Informational campaigns that focus on positively framing reclaimed water instead of conjuring its stigma-inducing aspects have had considerable success. NEWater in Singapore, for example, has used this approach, enabling Signapore to obtain approximately $40 \%$ of its water from water reclamation (Lee and Tan 2016; PUB Singapore’s National Water Agency 2018). In addition to changing the terminology, NEWater's strategy to gain broad public acceptance included bottling the water and handing it out at community events to allow people to taste it (Lee and Tan 2016). Still, key questions remain about how reclaimed water should be branded in the United States and elsewhere.

This study addresses three key questions:

1. What names for reclaimed water are most favorably and least favorably perceived by consumers?

2. Does an opportunity to taste reclaimed water affect how consumers view various potential names for it?

3. Does the type of water consumers typically drink affect how they perceive potential brand names for reclaimed water?

Table 1 summarizes the hypotheses associated with these questions and the results of the studies in rejecting the null hypotheses. Strikingly, the names often used to refer to this water, such as Reused, Treated, Nontraditional, Reclaimed, and Recycled, all score quite low. We find that names that invoke desirable characteristics of the water—pure, fresh, and natural—are preferred; Pure, Eco-Friendly, and Advanced Purified were viewed as most favorable of the 
options tested. Having an opportunity to taste reclaimed water seems to clarify people's preferences as it increases the degree of difference in their preferences for various labels. Consumers who typically drink bottled water show a significant preference for the name All Fresh and decreased favorability for the name Eco-Friendly.

\section{Research Design}

\subsection{Study $I$}

To assess consumers' preferences for different names for reclaimed water, we first compiled a list of all the names used in the literature and currently used to market reclaimed water to consumers throughout the world. We then shared that list with colleagues on the CONSERVE project $^{5}$ and asked them to edit and add to it. This process was intended to explore a wide array of names and it generated a final list of twenty-one names that were used in a survey that employed a five-point Likert scale (see Table 2 for the complete list of names). The survey was administered to 305 adult respondents recruited at a local farmers' market and at a shopping mall. To avoid forcing each participant to provide responses for all twenty-one names, each was shown a randomly selected group of six names on their tablet screen when asked to respond to the following question (see Appendix A-1):

"Being able to drink treated wastewater is a possibility available to consumers. This drinking water has been referred to by several different names. On a scale of 1 (least favorable) to 5 (most favorable), please

\footnotetext{
${ }^{5}$ CONSERVE is comprised of bioscientists, engineers, economists, social-behavioral scientists, law and policy experts, extension specialists, educational media developers, and computer scientists (http://conservewaterforfood.org/)
} 
indicate how favorable you consider each of following names for this water."

Each participant $i$ has a true favorability score $y^{*}$ for each name $j$. We cannot directly observe $y^{*}$ but can observe the categories of response, $y(1=$ least favorable to $5=$ most favorable), which can be formalized as

$$
y_{i j}=\left\{\begin{array}{l}
1 \text { if } y_{i j}^{*} \leq \mu_{1} \\
2 \text { if } \mu_{1}<y_{i j}^{*} \leq \mu_{2}, \\
3 \text { if } \mu_{2}<y_{i j}^{*} \leq \mu_{3} \\
4 \text { if } \mu_{3}<y_{i j}^{*} \leq \mu_{4} \\
5 \text { if } \mu_{4}<y_{i j}^{*}
\end{array}\right.
$$

If the externally imposed endpoint $\mu_{1}$ is greater than or equal to a participant's true favorability score, $y_{i j}^{*}$, the participant chooses the Likert scale value of 1 . Otherwise, participants move up the Likert scale until they either find a $\mu_{n}(n=1,2,3,4,5)$ that is greater than or equal to $y_{i j}^{*}$ or reach $\mu_{4}$, decide it is less than $y_{i j}^{*}$, and choose the Likert scale value of 5 .

\subsection{Study II}

In the second study, we used the same stated-preference, five-point Likert scale question described above for Study I to elicit participants’ perceptions. Based on the analysis of the data from Study I, we were able to identify the six most-favored potential brand names for reclaimed water and showed participants each of these. Tablet computers presented 907 adult participants with the six names on a single screen (see Appendix A-2): Pure, All Natural, 100\% Fresh, All Fresh, Eco-Friendly, and Advanced Purified. Presentation of the names on the screen was randomized to eliminate ordering effects. To avoid bias associated with the discovered 
preference hypothesis (Plott 1996), participants could go back and change their ratings after considering all six names.

Recruitment for the second study took place at a large agricultural community event held in the Mid-Atlantic region of the United States that attracts approximately 8,000 people from at least eighteen states each year. The room in which the study took place was partitioned in two with the treatment group on one side and the control on the other, with participants being randomly assigned to each.

The treatment group was given an opportunity to drink potable reclaimed water 6 , provided in a three-ounce cup, at the beginning of the study. The water was dispensed from a clear glass jug located on a table on the treatment group's side of the room. Of the 453 treatmentgroup participants, 355 (78\%) tried the water and were asked to rate its taste and overall quality compared to the water they typically drink on a scale from 1 (worse) to 5 (better) with 3 indicating that it was the same (see Appendix A-3). Participants who chose not to drink the water were asked to dispose of the cup when they finished the survey. The 454 participants in the control group were not given the opportunity to taste the reclaimed water and could not observe the treatment group.

After rating the favorability of the six potential names for reclaimed water, participants completed a survey that collected information on their demographic characteristics, political views, and opinions on relevant topics (see Appendix B for the complete survey). Before leaving, each participant received a gift certificate for a free ice cream cone, worth approximately $\$ 3$, to a local creamery within walking distance as compensation for their time.

\footnotetext{
${ }^{6}$ The potable reclaimed water was obtained from the Prima County Regional Wastewater Reclamation Department in Tuscon, Arizona through collaborators on the CONSERVE project.
} 


\section{Results}

\subsection{Study I}

In Study I, 305 adult participants rated the favorability of six potential names for reclaimed water, generating 1,814 observations (some participants did not rate all the names presented). Table 2 presents summary statistics for the demographic characteristics of this sample and the number of participants who saw and rated each branding name. Since the six names shown to each participant was determined randomly, there was some variation in how many times each of the twenty-one names was rated. For instance, All Natural and Fresh2O were presented to the largest number of participants (99). Figure 1 displays the mean favorability rating for each name and its associated 95\% confidence interval. The figure shows that the top six names—Pure, All Natural, 100\% Fresh, All Fresh, Eco-Friendly, and Advanced Purified—stood out strongly for participants since their means and the lower bounds of the confidence intervals were all greater than 3.00, the middle value of the Likert scale. Interestingly, five of the six least favorable names were the terms most commonly used by scientists, agricultural producers, and water utilities (Recycled, Reclaimed, Nontraditional, Treated Wastewater, Reused). Also striking is how adding "Pure" to "Recycled" moved the favorability ranking from sixteenth (2.39) to seventh (3.11).

Given the ordered nature of the data ( 1 = least favorable and 5 = most favorable), we used an ordered logit model to test for significance between the names. To account for the within-subject comparisons, we implemented a random-effects specification and estimated the coefficients using clustered standard errors. The model is formalized as:

$$
\operatorname{Pr}\left(y_{i j}>n \mid \mu, x_{i j}, v_{i}\right)=H\left(\beta * \mathbf{x}_{i j}+v_{i}-\mu_{N}\right)
$$


where $v_{i}$ is independently and identically distributed, $\mathrm{N}\left(0, \sigma_{v}^{2}\right)$, and $H(\cdot)$ is the logistic cumulative distribution function. In this specification, $y_{i j}$ is the categorical favorability score for participant $i$ for branding name $j, \mu$ is a set of cut points $\mu_{1}, \ldots \mu_{N-1}, N$ is the number of possible outcomes (five in this case), $\mathrm{x}_{i j}$ is a matrix of dummy variables for participant $i$ and branding name $j$ with Reused (the least favored of the twenty-one names) as the omitted variable, and $v_{i}$ includes panel-level random effects.

The estimated coefficients from equation 2 and the results of the Wald tests of whether there are significant differences between the coefficients of the branding names are presented in Table 3. Those values show that the top six names are significantly different, at a 5\% level, from most of the other names. Exceptions are the seventh ranked name (Pure Recycled), which has a coefficient similar to that of the fourth, fifth, and sixth ranked names (All Fresh, Eco-Friendly, and Advanced Purified), and the sixth ranked name (Advanced Purified), which has a coefficient that is similar to the second and third ranked names. To trim the number of names tested in the second study, we selected the top six ranked names since they largely stood out from the rest. The positively viewed names predominantly invoked physical characteristics of the water (pure, fresh, natural) rather than the processes used (recycled, reclaimed, treated, reused), which aligns with the characteristics typically used to market bottled water. It was the names that emphasized the processes the water had gone through that had the smallest coefficients. In contrast to 
previous studies, there were no significant differences between any of these names (Menegaki et al. 2009; Rock, Solop, and Gerrity 2012)

\subsection{Study II}

The 907 adult participants in the second study rated each of the top six branding names identified in Study I, yielding 5,442 observations. Table 4 presents summary statistics for the treatmentspecific variables and the demographic characteristics of the sample. Of the 453 participants in the treatment group, $78 \%$ tried the water, and on average they rated the water as having the same taste and quality as the water they typically drink.

The mean favorability coefficients (with 95\% confidence intervals) presented in Figure 2 and paired t-tests reveal that participants in the control and the treatment group liked the name All Fresh least. Looking at the treatment group, we see more-distinct preferences for the names than in the control group. The most preferred name being Pure, followed by Eco-Friendly, and Advanced Purified. These three names were scored significantly more favorable than All Natural and 100\% Fresh, which are not significantly different from one another.

To examine the effects of the tasting treatment further and determine any potential relationships between participants' favorability ratings of the names and the type of water they typically drink, we analyzed an iteration of equation 2 that incorporated additional independent variables and interaction terms (see Table 5) for the full sample, the treatment group, and the treatment group participants who tried the water. Having an opportunity to try reclaimed water increases participants' favorability of the name Eco-Friendly, relative to the rating by the control group. We also find that participants' trying this water does not increase their favorability ratings relative to having the opportunity and not taking it. However, among those participants who tried 
the water, there is a significant difference in favorability for Eco-Friendly (preferred) and Advanced Purified, whereas, there are no significant differences in preferences for the top five names (Pure, Eco-Friendly, Advanced Purified, 100\% Fresh, and All Natural) by those in the treatment group who did not try the water. Furthermore, based on the results of two-sample ttests, there is a significant difference in favorability between the control group and those in the treatment group who tried the water for $100 \%$ Fresh and Eco-Friendly, but no significant difference for any of the names between the control group and those in the treatment group who did not try the water.

We do find evidence of a relationship between typically choosing to drink bottled water, rather than tap water, and several of the potential names. The most-robust effects are for All Fresh (increased favorability) and Eco-Friendly (decreased favorability). This may be related to perceptions of bottled water being better, fresher than tap water (Wilk 2006) and Eco-Friendly potentially reminding consumers that bottled water has a negative effect on the environment (Horowitz, Frago, and Mu 2018).

\section{Conclusions}

Increasingly scarce supplies of water in the United States and across the globe have precipitated the need for new sources of potable and irrigation water. Reclaimed water has been presented as a cost-effective, reliable, and safe solution to water shortages, but consumers, upon learning that such water is or will be used for drinking or producing their food, require either a significant reduction in price to purchase or consume such products or reject them outright. Consequently, reclaimed water cannot be adopted on a large scale until ways are found to make it acceptable to consumers. Prior studies have examined consumer perceptions of a few names used 
interchangeably by scientists, agricultural producers, and water utilities but none have compared consumers’ perceptions of those names to brand names currently used to market reclaimed drinking water, names suggested by researchers who have addressed this problem, or variations commonly found on food labels.

Using stated-preference data collected from 305 adults, we first tested consumers’ preferences for twenty-one potential branding names for reclaimed water to identify the six most-favorable names: Pure, All Natural, 100\% Fresh, All Fresh, Eco-Friendly, and Advanced Purified, which invoke desirable qualities of water (pure, fresh, natural) that are commonly used to market bottled drinking water. The least favorable names—Recycled, Reclaimed, Treated, and Reused — refer to processes used on wastewater and five of the six least favorable names are the most commonly used terms by scientists and industry (Recycled, Reclaimed, Nontraditional, Treated Wastewater, Reused). The name Recycled, however, moves from sixteenth most favorable to seventh when Pure is added, an indication of the branding power of the word "pure" for reclaimed water products.

We then tested consumers' preferences for the top six names and analyzed whether an opportunity to taste reclaimed water effected participants' preferences for the names in a field study involving 907 adults. Overall, participants most preferred Pure, Eco-Friendly, and Advanced Purified and the 78\% of the treatment group participants who tried the reclaimed water particularly favored Pure. Analysis of the Study I survey data also revealed Pure as the highest ranked name whereas Eco-Friendly and Advanced Purified were ranked fifth and sixth.

We further found that typically drinking bottled water rather than tap water, had a significant effect on participants' favorability of some of the names, particularly with All Fresh Water (increasing favorability) and Eco-Friendly Water (decreasing favorability). All Fresh may 
be eliciting a trait that consumers already equate with bottled water and Eco-Friendly may remind participants of the negative environmental effects of bottled water. However, further research is needed to explore this relationship.

These findings present valuable information for policymakers and members of the food industry interested in encouraging widespread acceptance of reclaimed water for various applications. As evident from our results, consumers are more likely to accept reclaimed water if its branding uses terms associated with the quality of the water (pure, fresh, natural) and suggests that terms often used by scientists and industry to describe reclaimed water (recycled, reclaimed, treated, and reused) have negative associations for consumers. Finally, if one word stood out in the results it was the word Pure, which seemed to draw the most favorable response. 


\section{References}

Aschemann-Witzel, J., P. Varela, and A.O. Peschel. 2018. “Consumers’ categorization of food ingredients: Do consumers perceive them as 'clean label' producers expect? An exploration with projective mapping.” Food Quality and Preference 71: 117-28. doi:10.1016/j.foodqual.2018.06.003.

Asioli, D., J. Aschemann-Witzel, V. Caputo, R. Vecchio, A. Annunziata, T. Næs, and P. Varela. 2017. "Making sense of the "clean label" trends: A review of consumer food choice behavior and discussion of industry implications.” Food Research International 99: 5871. doi:10.1016/j.foodres.2017.07.022.

Bakopoulou, S., I. Katsavou, S. Polyzos, and A. Kungolos. 2008. “Using Recycled Water for Agricultural Purposes in the Thessaly Region, Greece: A Primary Investigation of Citizens’ Opinions.” WIT Transactions on Ecology and the Environment 109: 869-78. https://doi.org/10.2495/WM080881.

Chen, W., S. Lu, W. Jiao, M. Wang, and A.C. Chang. 2013. "Reclaimed Water: A Safe Irrigation Water Source?” Environmental Development 8: 74-83.

Clarke, T. 2007. Inside the Bottle: Exposing the Bottled Water Industry. 2nd ed. Canadian Centre for Policy Alternatives.

Costanigro, M., O. Deselnicu, and S. Kroll. 2015. “Food beliefs: Elicitation, estimation and implications for labeling policy.” Journal of Agricultural Economics 66 (1): 108-128.

Dery, J.L., Suri, M.R., Brassil, N., Pee, D., Goeringer, P., Sapkota, A.R., Rock, C., Rosenberg Goldstein, R.E. 2018. Recycled water and related terms relevant for agriculture. http://conservewaterforfood.org/extension/.

Detre, J.D., and M.A. Gunderson. 2012. "Did the "Pink Slime” Controversy Influence Publicly Traded Agribusiness Companies.” Choices 27(4): 1-4. www.jstor.org/stable/choices.27.4.04.

Ellis, S.F., M. Kecinski, K.D. Messer, and C. Lipchin. 2017. “Gaps in Risk Perceptions Between the United States and Israel: Field Experiments on Various Types of Nontraditional Water.” Society of Risk Analysis Annual Meeting, Arlington, VA.

Faulconer, K. 2017. “San Diego’s Pure Water Program: A sustainable solution to water supply challenges.” Brookings. Accessed July 3, 2018. https://www.brookings.edu/blog/theavenue/2017/05/18/san-diegos-pure-water-program-a-sustainable-solution-to-watersupply-challenges/.

Fielding, K.S., S. Dolnicar, and T. Schultz. 2018. "Public Acceptance of Recycled Water.” International Journal of Water Resources Development: 1-36. https://doi.org/10.1080/07900627.2017.1419125. 
Greene, J.L. 2012. "Lean Finely Textured Beef: The "Pink Slime” Controversy." Congressional Research Service, Accessed June 30, 2018. https://digital.library.unt.edu/ark:/67531/metadc85402/.

Hawkins, G. 2009. “THE POLITICS OF BOTTLED WATER.” Journal of Cultural Economy 2, nos. 1-2: 183-95. doi:10.1080/17530350903064196.

Horowitz, N., J. Frago, and D. Mu. 2018. "Life cycle assessment of bottled water: A case study of Green2O products.” Waste Management 76: 734-43. doi:10.1016/j.wasman.2018.02.043.

Hu, Z., L.W. Morton, and R.L. Mahler. 2011. "Bottled Water: United States Consumers and Their Perceptions of Water Quality.” International Journal of Environmental Research and Public Health 8(2): 565-78. doi:10.3390/ijerph8020565.

Hui, I., and B. E. Cain. 2017. "Overcoming Psychological Resistance toward Using Recycled Water in California: Recycled Water in California.” Water and Environment Journal, https://doi.org/10.1111/wej.12285.

Hummer, N., and S. Eden. 2016. “Potable Reuse of Water.” Arroyo, Accessed July 10, 2018. http://wrrc.arizona.edu/publications/arroyo-newsletter/arroyo-2016-Potable-Reuse-ofWater.

Kanter C., K.D. Messer, and H.M. Kaiser. 2009. "Does Production Labeling Stigmatize Conventional Milk?” American Journal of Agricultural Economics 91(4):1097-1109.

Katz, B., and L.A. Williams. 2011. “Cleaning up processed foods.” Food Technology 65(12): 3337. https://www.scopus.com/record/display.uri?eid=2-s2.084855799496\&origin=inward\&txGid=712f7706488e41d03bfd1f754749e4c4.

Kecinski, M., Kerley, D., K.D. Messer, and W.D. Schulze. 2016. "Stigma Mitigation and the Importance of Redundant Treatments.” Journal of Economic Psychology. 54: 44-52. doi:10.1016/j.joep.2016.02.003.

Kecinski, M., and K.D. Messer. 2017. "Social Preferences and Communication as Stigma Mitigation Devices - Evidence from Recycled Drinking Water Experiment.” Applied Economics and Statistics Research Report, University of Delaware, RR17-06.

Lee, H., and T.P. Tan. 2016. "Singapore’s experience with reclaimed water: NEWater." International Journal of Water Resources Development 32 (4): 611-21. doi:10.1080/07900627.2015.1120188.

Lusk, J.L., T.C. Schroeder, and G.T. Tonsor. 2014. "Distinguishing beliefs from preferences in food choice." European Review of Agricultural Economics 41 (4): 627-655.

McKendree, M.G.S., D. Widmar, and N. Widmar. 2014. "Quantifying Consumers' Perceptions of Lean Finely Textured Beef.” Working Papers 14 (3). Accessed June 30, 2018. https://ideas.repec.org/p/pae/wpaper/14-3.html. 
Mekonnen, M.M., and A.Y. Hoekstra. 2016. "Four billion people facing severe water scarcity." Science Advances 2 (2). Accessed July 9, 2018. doi:10.1126/sciadv.1500323.

Menegaki, A.N., N. Hanley, and K. P. Tsagarakis. 2007. “The Social Acceptability and Valuation of Recycled Water in Crete: A Study of Consumers’ and Farmers’ Attitudes.” Ecological Economics 62 (1): 7-18.

Menegaki, A.N., R.C. Mellon, A. Vrentzou, G. Koumakis, and K.P. Tsagarakis. 2009. “What’s in a Name: Framing Treated Wastewater as Recycled Water Increases Willingness to use and Willingness to Pay.” Journal of Economic Psychology 30 (3): 285-292.

Messer, K.D., M. Costanigro, and H. Kaiser. 2017. "Labeling Food Processes: The Good, the Bad and the Ugly.” Applied Economics Perspectives and Policy. 39(3): 407-427.

Morgan, E.A., and D. Grant-Smith. 2015. “Tales of Science and Defiance: The Case for CoLearning and Collaboration in Bridging the Science/Emotion Divide in Water Recycling Debates.” Journal of Environmental Planning and Management 58 (9-10): 1770-1788.

Plott, C.R. 1996. "Rational Individual Behavior in Markets and Social Choice Processes: The Discovered Preference Hypothesis,” in Rational Foundations of Economic Behavior. K. Arrow, E. Colombatto, M. Perleman, and C. Schmidt, eds. London: Macmillan and NY: St. Martin’s, pp. 225-250.

PUB Singapore’s National Water Agency. 2018. NEWater. Accessed July 11, 2018 at https://www.pub.gov.sg/watersupply/fournationaltaps/newater.

Rock, C., J.E. McLain, and D. Gerrity. 2012. "Water Recycling FAQs,” http://arizona.openrepository.com/arizona/bitstream/10150/225869/3/az1568-2012.pdf.

Rock, C., F. Solop, and D. Gerrity. 2012. "Survey of statewide public perceptions regarding water reuse in Arizona.” Journal of Water Supply: Research and Technology-AQUA 61(8).

Rozin, P., B. Haddad, C. Nemeroff, and P. Slovic. 2015. "Psychological Aspects of the Rejection of Recycled Water: Contamination, Purification and Disgust.” Judgment and Decision Making 10 (1): 50-63.

Savchenko, O., M. Kecinski, T. Li, and K.D. Messer. 2018a. "Reclaimed Water and Food Production: Cautionary Tales from Consumer Research”. Unpublished manuscript.

Savchenko, O., M. Kecinski, T. Li, K.D. Messer, and H. Xu. 2018b. "Fresh Foods with Recycled Water: A Framed Field Experiment on Consumer Response.” Applied Economics \& Statistics Research Report, University of Delaware, RR18-03.

Smith, A.F. 2013. “The Only Proper Drink for Man.” In Drinking History. N.p.: Columbia University Press. http://www.jstor.org/stable/10.7312/smit15116.19. 
The Source Magazine. "Bottles of purified recycled water hit the streets of Los Angeles.” Last modified August 11, 2017. Accessed July 3, 2018. www.thesourcemagazine.org/bottlespurified-recycled-water-hit-streets-los-angeles/.

Uhlmann, V., and B.W. Head. 2011. "Water Recycling: Recent History of Local Government Initiatives in South East Queensland.” Urban Water Security Research Alliance Technical Report No. 45. http://www.urbanwateralliance.org.au/publications/uwsratr45.pdf.

U.S. Department of Agriculture (USDA). 2017. "Water for Food Production Systems Challenge Area: Fiscal Year 2017, Request for Applications.” https://nifa.usda.gov/sites/def ault/files/rfa/FY2017_AFRI_Water_for\%20Food\%20Production\%20Systems.pdf

U.S. Department of Agriculture Economic Research Service (USDA ERS). 2017. "Irrigation \& Water Use.” April 28, 2017. https://www.ers.usda.gov/topics/farm-practicesmanagement/irrigation-water-use.aspx.

Wanctin, L., K. Dalmeny, and J. Longfield. 2006. Have you bottled it? How drinking tap water can help save you and the planet. London, England: Sustain Publication.

WateReuse. 2018. “Glossary.” Accessed July 3, 2018. https://watereuse.org/water-reuse101/glossary/.

Wilk, R. 2006. "Bottled Water: The pure commodity in the age of branding.” Journal of Consumer Culture. doi:10.1177/1469540506068681.

World Bank. 2014. Water resources management: Sector results profile. Accessed June 29, 2017, at http://www.worldbank.org/en/results/2013/04/15/water-resources-management-resultsprofile.

World Water Assessment Programme. 2016. The United Nations World Water Development Report 2016: Water and Jobs. Paris, UNESCO. 
Figure 1. Mean favorability and 95\% confidence intervals of Study I names

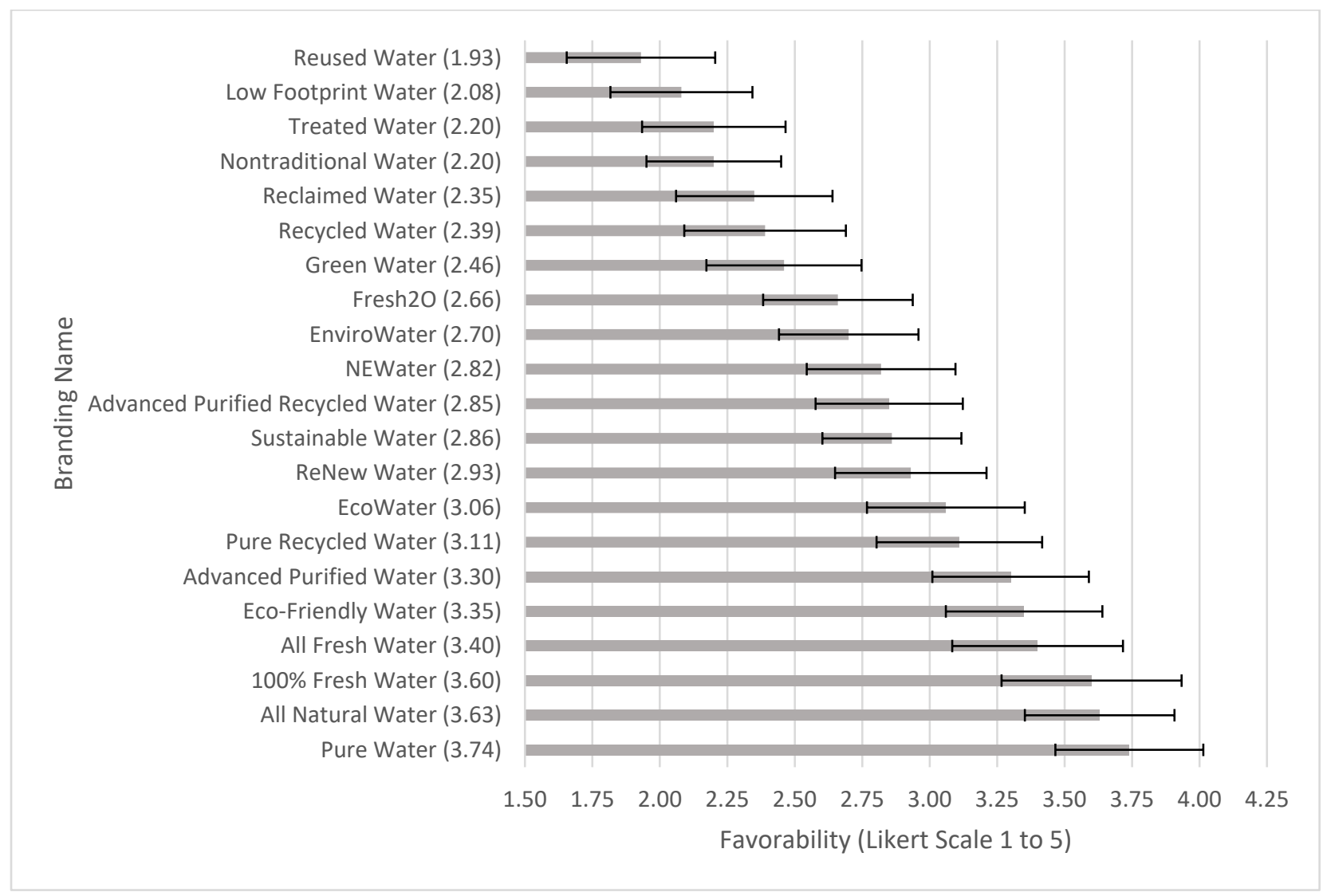


Figure 2. Mean favorability and $95 \%$ confidence intervals of Study II names

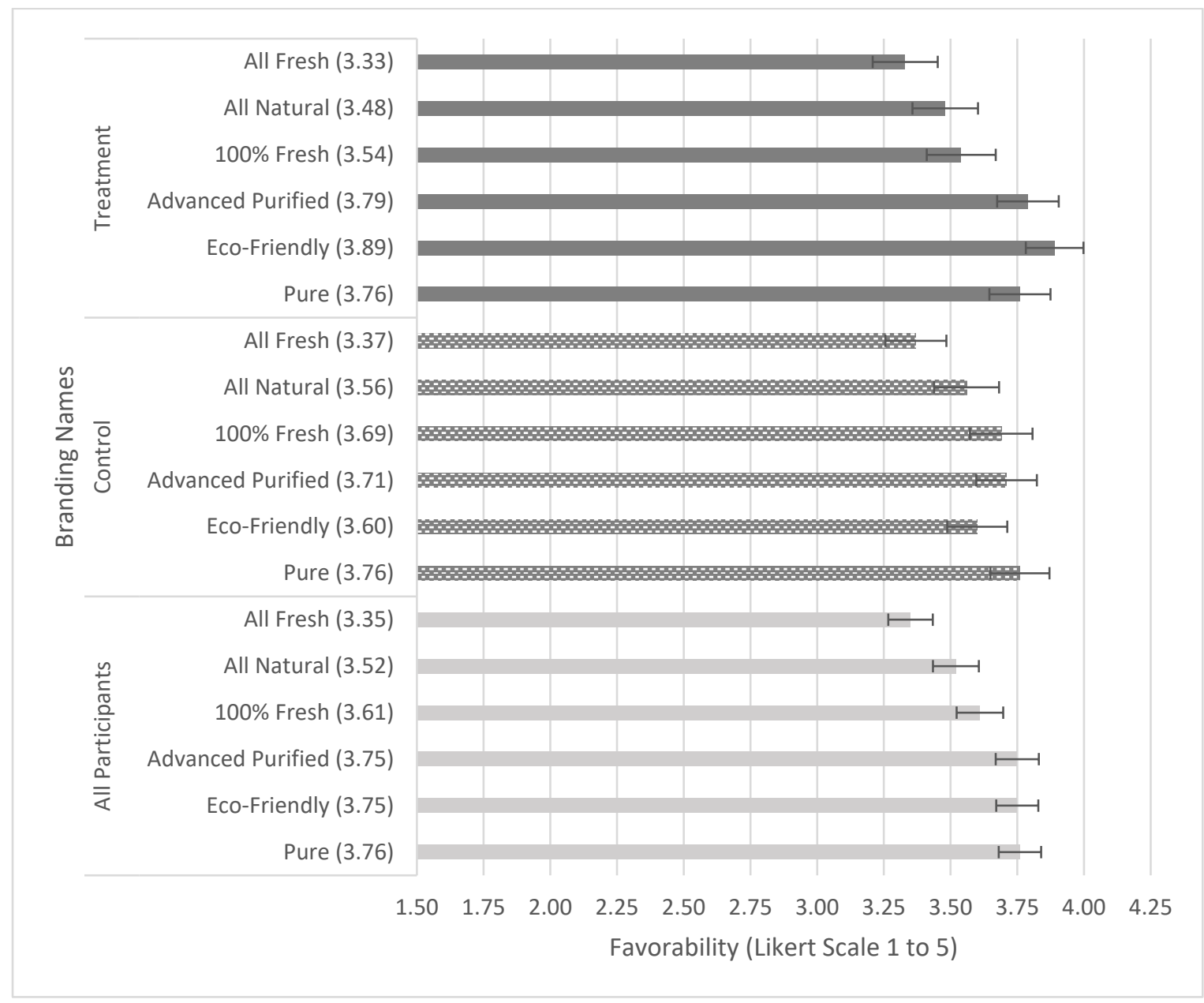




\section{Table 1. Research Questions and Results}

\begin{tabular}{|c|c|c|}
\hline Question & Hypothesis Statement & Results \\
\hline $\begin{array}{l}\text { 1. What names for reclaimed } \\
\text { water are most favorably and } \\
\text { least favorably perceived by } \\
\text { consumers? }\end{array}$ & $\begin{array}{l}\text { For each branding name } a \text { and all other } \\
\text { branding names } b \\
H_{0}: \text { Favorability }_{a}=\text { Favorability }_{b} \\
H_{A}: \text { Favorability }_{a} \neq \text { Favorability }_{b}\end{array}$ & $\begin{array}{l}\text { Reject } H_{0} \text { (Tables 2, 5, and } \\
\text { C-1). The three most } \\
\text { favorable names are Pure, } \\
\text { Eco-Friendly, and } \\
\text { Advanced Purified. The } \\
\text { least favorable were } \\
\text { Recycled, Reclaimed, } \\
\text { Nontraditional, Treated } \\
\text { Wastewater, and Reused. }\end{array}$ \\
\hline $\begin{array}{l}\text { 2. Does the opportunity to taste } \\
\text { reclaimed water affect how } \\
\text { consumers view various } \\
\text { potential names for it? }\end{array}$ & $\begin{array}{l}\text { For each branding name } a \text {, control } c \text {, and } \\
\text { treatment } d \\
H_{0}: \text { Favorability }{ }_{a}^{c}=\text { Favorability } \\
H_{A}: \text { Favorability }_{a}^{c} \neq \text { Favorability }_{a}^{d}\end{array}$ & $\begin{array}{l}\text { Reject } H_{0} \text { (Tables } 7 \text { and C- } \\
\text { 2). The opportunity to taste } \\
\text { reclaimed water clarifies } \\
\text { consumer preferences and } \\
\text { increases favorability for } \\
\text { Eco-Friendly. }\end{array}$ \\
\hline $\begin{array}{l}\text { 3. Does the type of water } \\
\text { consumers typically drink affect } \\
\text { how they perceive potential } \\
\text { brand names for reclaimed } \\
\text { water? }\end{array}$ & $\begin{array}{l}\text { For each branding name } a \text {, water type } e \text {, and } \\
\text { all other water types } f \\
H_{0}: \text { Favorability }_{a}^{e}=\text { Favorability } \\
H_{A}: \text { Favorability }_{a}^{e} \neq \text { Favorability }_{a}^{f}\end{array}$ & $\begin{array}{l}\text { Reject } H_{0} \text { (Table } 7 \text { ). } \\
\text { Participants favorability of } \\
\text { certain names was } \\
\text { significantly different if } \\
\text { they typically drink bottled } \\
\text { water instead of tap water. }\end{array}$ \\
\hline
\end{tabular}


Table 2. Summary Statistics for Study I

\begin{tabular}{|c|c|c|c|c|}
\hline & & & Branding Name & Participants Who Rated \\
\hline & Total Participants & 305 & Pure Water & 97 \\
\hline & & & All Natural Water & 99 \\
\hline \multirow[t]{5}{*}{ Age } & Minimum & 18 & $100 \%$ Fresh Water & 75 \\
\hline & Median & 35 & All Fresh Water & 82 \\
\hline & Mean & 38 & Eco-Friendly Water & 82 \\
\hline & Maximum & 99 & Advanced Purified Water & 82 \\
\hline & & & Pure Recycled Water & 93 \\
\hline \multirow[t]{6}{*}{ Income } & Minimum & $<\$ 14,999$ & EcoWater & 88 \\
\hline & Median & $\$ 35,000-\$ 49,000$ & ReNew Water & 90 \\
\hline & Mean & $\$ 35,000-\$ 49,000$ & Sustainable Water & 90 \\
\hline & Махітит & $>\$ 250,000$ & Advanced Purified & \\
\hline & & & Recycled Water & 87 \\
\hline & & & NEWater & 84 \\
\hline \multirow[t]{2}{*}{ Gender } & Female & $52 \%$ & EnviroWater & 88 \\
\hline & & & Fresh2O & 99 \\
\hline Educational & High School or Less & $32 \%$ & Green Water & 81 \\
\hline \multirow[t]{5}{*}{ Attainment } & Some College & $31 \%$ & Recycled Water & 84 \\
\hline & Associate Degree & $10 \%$ & Reclaimed Water & 75 \\
\hline & Bachelor's Degree & $14 \%$ & Nontraditional Water & 84 \\
\hline & Graduate Degree & $13 \%$ & Treated Wastewater & 86 \\
\hline & & & Low Footprint Water & 85 \\
\hline \multirow[t]{5}{*}{ Employment } & Unemployed & $10 \%$ & Reused Water & 83 \\
\hline & Employed & $70 \%$ & & \\
\hline & Retired & $6 \%$ & & \\
\hline & Disabled & $3 \%$ & & \\
\hline & Student & $11 \%$ & & \\
\hline Political & Liberal & $28 \%$ & & \\
\hline \multirow[t]{3}{*}{ Affiliation } & Moderate & $31 \%$ & & \\
\hline & Conservative & $27 \%$ & & \\
\hline & Other & $13 \%$ & & \\
\hline Drink Most & Bottled & $83 \%$ & & \\
\hline \multirow[t]{3}{*}{ Often } & Filtered Tap & $0 \%$ & & \\
\hline & Tap & $16 \%$ & & \\
\hline & Other & $1 \%$ & & \\
\hline
\end{tabular}




\section{Table 3. Results from Ordered Logit for Study I}

\begin{tabular}{llll}
\hline & Coef. & S.E. & Results of Wald Tests (Sig. Dif. 5\% Level) \\
\hline 1. Pure Water & $3.551^{* * *}$ & 0.366 & 567891011121314151617181920 \\
2. All Natural Water & $3.213^{* * *}$ & 0.351 & 57891011121314151617181920 \\
3. 100\% Fresh Water & $3.360^{* * *}$ & 0.426 & 57891011121314151617181920 \\
4. All Fresh Water & $2.936^{* * *}$ & 0.369 & 891011121314151617181920 \\
5. Eco-Friendly Water & $2.630^{* * *}$ & 0.319 & 12391011121314151617181920 \\
6. Advanced Purified Water & $2.684^{* * *}$ & 0.344 & 191011121314151617181920 \\
7. Pure Recycled Water & $2.358^{* * *}$ & 0.356 & 1231314151617181920 \\
8. EcoWater & $2.262^{* * *}$ & 0.312 & 12341314151617181920 \\
9. ReNew Water & $1.888^{* * *}$ & 0.324 & 123456151617181920 \\
10. Sustainable Water & $1.936^{* * *}$ & 0.301 & 123456151617181920 \\
11. Advanced Purified Recycled Water & $2.044^{* * *}$ & 0.306 & 123456151617181920 \\
12. NEWater & $1.944^{* * *}$ & 0.327 & 123456151617181920 \\
13. EnviroWater & $1.574^{* * *}$ & 0.312 & 123456781617181920 \\
14. Fresh2O & $1.667^{* * *}$ & 0.334 & 123456781617181920 \\
15. Green Water & $1.206^{* * *}$ & 0.303 & 123456789101112 \\
16. Recycled Water & $0.974^{* * *}$ & 0.292 & 1234567891011121314 \\
17. Reclaimed Water & $1.040^{* * *}$ & 0.289 & 1234567891011121314 \\
18. Nontraditional Water & $0.755^{* * *}$ & 0.281 & 1234567891011121314 \\
19. Treated Wastewater & $0.803^{* * *}$ & 0.295 & 1234567891011121314 \\
20. Low Footprint Water & $0.671^{* *}$ & 0.315 & 1234567891011121314 \\
Total N & 1,814 & & \\
Total Participants & 305 & & \\
\hline *** Signficant at the 1\% & & \\
\hline
\end{tabular}

***Significant at the $1 \%$ level **Significant at the $5 \%$ level * Significant at the $10 \%$ level

Note: Names are ranked by mean favorability score, with Pure Water having the highest and Reused Water, the omitted variable, the lowest. 


\section{Table 4. Summary Statistics for Study II}

\begin{tabular}{|c|c|c|}
\hline & Total Participants & 907 \\
\hline \multirow[t]{4}{*}{ Treatment } & Total Participants & 453 \\
\hline & Tried Recycled Water & $78 \%$ \\
\hline & Taste Rating (compared to water you typically drink) & Same \\
\hline & Overall Quality Rating (compared to water you typically drink) & Same \\
\hline \multirow[t]{4}{*}{ Age } & Minimum & 18 \\
\hline & Median & 24 \\
\hline & Mean & 32 \\
\hline & Maximum & 100 \\
\hline \multirow[t]{4}{*}{ Income } & Minimum & $<\$ 14,999$ \\
\hline & Median & $\$ 75,000-\$ 99,999$ \\
\hline & Mean & $\$ 50,000-\$ 74,999$ \\
\hline & Maximum & $>\$ 250,000$ \\
\hline Gender & Female & $68 \%$ \\
\hline Educational & High School or Less & $2 \%$ \\
\hline \multirow[t]{4}{*}{ Attainment } & Some College & $31 \%$ \\
\hline & Associate Degree & $5 \%$ \\
\hline & Bachelor's Degree & $28 \%$ \\
\hline & Graduate Degree & $23 \%$ \\
\hline \multirow[t]{6}{*}{ Employment } & Unemployed & $4 \%$ \\
\hline & Employed & $48 \%$ \\
\hline & Retired & $4 \%$ \\
\hline & Stay at Home Parent & $3 \%$ \\
\hline & Disabled & $0 \%$ \\
\hline & Student & $40 \%$ \\
\hline \multirow[t]{4}{*}{ Political Affiliation } & Liberal & $44 \%$ \\
\hline & Moderate & $36 \%$ \\
\hline & Conservative & $15 \%$ \\
\hline & Other & $5 \%$ \\
\hline \multirow[t]{6}{*}{ Heard About } & Pure & $59 \%$ \\
\hline & All Natural & $53 \%$ \\
\hline & $100 \%$ Fresh & $40 \%$ \\
\hline & All Fresh & $33 \%$ \\
\hline & Eco Friendly & $30 \%$ \\
\hline & Advanced Purified & $40 \%$ \\
\hline \multirow[t]{4}{*}{ Drink Most Often } & Bottled & $21 \%$ \\
\hline & Filtered Tap & $53 \%$ \\
\hline & Tap & $26 \%$ \\
\hline & Other & $0 \%$ \\
\hline
\end{tabular}


Table 5. Results from Ordered Logit for Study II

\begin{tabular}{|c|c|c|c|c|c|c|c|}
\hline & \multicolumn{2}{|c|}{ All Participants } & \multicolumn{2}{|c|}{ Treatment Only } & \multicolumn{2}{|c|}{ Tried the Water } \\
\hline & & Coef. & S.E. & Coef. & S.E. & Coef. & S.E. \\
\hline Water & Pure Water & $0.824 * * *$ & 0.171 & $0.982 * * *$ & 0.307 & $0.627 * * *$ & 0.210 \\
\hline \multirow[t]{4}{*}{ Type } & All Natural Water & $0.563^{* * *}$ & 0.153 & $0.773 * * *$ & 0.258 & 0.296 & 0.190 \\
\hline & 100\% Fresh Water & $0.663^{* * *}$ & 0.137 & $0.718 * * *$ & 0.260 & 0.265 & 0.189 \\
\hline & Eco-Friendly Water & $0.756^{* * *}$ & 0.181 & $1.365^{* * *}$ & 0.343 & $1.552^{* * *}$ & 0.280 \\
\hline & Advanced Purified Water & $0.564 * * *$ & 0.214 & $1.029 * * *$ & 0.355 & $0.630 * *$ & 0.275 \\
\hline \multirow[t]{14}{*}{ Treatment } & Treatment & 0.038 & 0.143 & & & & \\
\hline & Treatment*Pure & 0.322 & 0.155 & & & & \\
\hline & Treatment*All Natural & -0.109 & 0.144 & & & & \\
\hline & Treatment*100\% Fresh & -0.193 & 0.126 & & & & \\
\hline & Treatment*Eco-Friendly & $0.511 * * *$ & 0.172 & & & & \\
\hline & Treatment*Advanced Purified & 0.225 & 0.197 & & & & \\
\hline & Try & & & 0.164 & 0.249 & & \\
\hline & Try*Pure & & & -0.163 & 0.277 & & \\
\hline & Try*All Natural & & & -0.402 & 0.248 & & \\
\hline & Try*100\% Fresh & & & -0.375 & 0.231 & & \\
\hline & Try*Eco-Friendly & & & 0.122 & 0.296 & & \\
\hline & Try*Advanced Purified & & & -0.347 & 0.327 & & \\
\hline & Taste & & & & & -0.004 & 0.142 \\
\hline & Overall Quality & & & & & -0.141 & 0.161 \\
\hline Typically & Bottled & $0.779 * * *$ & 0.219 & $0.900 * * *$ & 0.308 & $0.875^{* *}$ & 0.364 \\
\hline \multirow[t]{13}{*}{ Drink } & Bottled*Pure & $-0.494 * *$ & 0.231 & -0.312 & 0.325 & 0.027 & 0.369 \\
\hline & Bottled*All Natural & -0.267 & 0.214 & -0.390 & 0.307 & -0.203 & 0.363 \\
\hline & Bottled*100\% Fresh & -0.109 & 0.191 & 0.147 & 0.291 & 0.202 & 0.334 \\
\hline & Bottled*Eco-Friendly & $-1.04 * * *$ & 0.246 & $-1.262 * * *$ & 0.378 & $-1.386 * * *$ & 0.348 \\
\hline & Bottled*Advanced Purified & $-0.575^{* *}$ & 0.274 & $-0.686^{*}$ & 0.382 & -0.667 & 0.444 \\
\hline & Filtered Tap & 0.181 & 0.170 & 0.265 & 0.240 & 0.286 & 0.267 \\
\hline & Filtered Tap*Pure & -0.072 & 0.184 & -0.178 & 0.246 & 0.094 & 0.268 \\
\hline & Filtered Tap*All Natural & $-0.297 *$ & 0.164 & -0.285 & 0.223 & -0.194 & 0.252 \\
\hline & Filtered Tap* $100 \%$ Fresh & -0.139 & 0.151 & -0.154 & 0.212 & -0.026 & 0.234 \\
\hline & Filtered Tap*Eco-Friendly & -0.237 & 0.206 & $-0.572 *$ & 0.306 & $-0.640 *$ & 0.348 \\
\hline & Filtered Tap*Advanced Purified & 0.241 & 0.234 & 0.281 & 0.316 & 0.380 & 0.357 \\
\hline & Total N & 5,442 & & 2,718 & & 2,130 & \\
\hline & Total Participants & 907 & & 453 & & 355 & \\
\hline
\end{tabular}

$* * *$ Significant at the $1 \%$ level $* *$ Significant at the $5 \%$ level $*$ Significant at the $10 \%$ level

Note: All Fresh Water is the omitted variable 


\section{Appendix A. Study questions}

Study Question A-1. Favorability question for Study $I^{7}$

Being able to drink treated wastewater is a possibility available to consumers. This drinking water has been referred to by several different names. On a scale of 1 (least favorable) to 5 (most favorable), please indicate how favorable you consider each of the following names for this water:

\section{Treated Water:}

$\begin{array}{ccccccc}\begin{array}{c}\text { Least } \\ \text { Favorable }\end{array} & 1 & 2 & 3 & 4 & 5 & \begin{array}{c}\text { Most } \\ \text { Favorable }\end{array}\end{array}$

\section{Reused Water:}

$\begin{array}{ccccccc}\begin{array}{c}\text { Least } \\ \text { Favorable }\end{array} & 1 & 2 & 3 & 4 & 5 & \begin{array}{c}\text { Most } \\ \text { Favorable }\end{array}\end{array}$

\section{All Natural Water :}

$\begin{array}{ccccccc}\begin{array}{c}\text { Least } \\ \text { Favorable }\end{array} & 1 & 2 & 3 & 4 & 5 & \begin{array}{c}\text { Most } \\ \text { Favorable }\end{array}\end{array}$

\section{NEWater :}

$\begin{array}{ccccccc}\begin{array}{c}\text { Least } \\ \text { Favorable }\end{array} & 1 & 2 & 3 & 4 & 5 & \begin{array}{c}\text { Most } \\ \text { Favorable }\end{array}\end{array}$

\section{Pure Water :}

$\begin{array}{ccccccc}\begin{array}{c}\text { Least } \\ \text { Favorable }\end{array} & 1 & 2 & 3 & 4 & 5 & \begin{array}{c}\text { Most } \\ \text { Favorable }\end{array}\end{array}$

\section{EcoWater :}

$\begin{array}{ccccccc}\begin{array}{c}\text { Least } \\ \text { Favorable }\end{array} & 1 & 2 & 0 & & 0 & \begin{array}{c}\text { Most } \\ \text { Favorable }\end{array} \\ & 1 & 2 & 3 & 4 & 5 & \end{array}$

\footnotetext{
${ }^{7}$ Every participant in Study I saw a different group of six potential brand names.
} 
Study Question A-2. Favorability question for Study II ${ }^{8}$

Being able to drink treated wastewater is a possibility available to consumers. This drinking water has been referred to by several different names. On a scale of 1 (least favorable) to 5 (most favorable), please indicate how favorable you consider each of the following names for this water:

Note that you have the opportunity to drink potable treated wastewater in the cup provided in front of you.

Least

Favorable
Most

Favorable

Pure Water

$100 \%$ Fresh Water

All Natural Water

All Fresh Water

Eco-Friendly Water

Advanced Purified Water

0

O

O

O

O

O
O

O

O

O

O

0
O

O

O

O

O

O
O

O

O

O

O

O
O

0

0

\section{Study Question A-3. Evaluation of reclaimed water sample ${ }^{9}$}

On a scale of 1 (Worse) to 5 (Better), how does the water you just tried compare to the water you typically drink, where 3 indicates the same:

Worse

Overall Quality

Taste

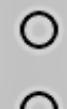

$\mathrm{O}$
Same

O

O
$\mathrm{O}$

O
Better

O

O

\footnotetext{
${ }^{8}$ This is the treatment groups version of the question. In the control group, the second sentence about having the opportunity to drink potable treated wastewater was not shown.

${ }^{9}$ This question was only shown to the participants in Study II's treatment group that tried the reclaimed water sample they were given. The ordering of "Overall Quality” and "Taste” was randomized across participants.
} 


\section{Appendix B. Survey for Study II}

1. What is your age?

2. What is your gender?

(C) Male

Female

3. What is your zip code?

4. What best describes your employment status?

Not employed, not looking for work

Not employed, looking for work

Employed, working 1-20 hours per week

E Employed, working 21-39 hours per week

Employed, working 40 or more hours per week

(C) Retired

(C) Student

Disabled, not able to work

C Stay at home parent/caregiver

5. Are you politically:

Liberal

(C) Moderate

Conservative

Other (please specify)

6. How would you identify your ethnicity?

C Non-Hispanic White

Hispanic or Latino

C Middle Eastern or Arab

black

6 East Asian

6 South Asian

(C) Pacific Islander

C Native American

Other (please specify) 
7. Which category best describes your household income (before taxes) in 2017 ?
Less than $\$ 14,999$
(C) $\$ 15,000-\$ 24,999$
(C) $\$ 25,000-\$ 34,999$
(C) $\$ 35,000-\$ 49,999$
(C) $\$ 50,000-\$ 74,999$
(C) $\$ 75,000-\$ 99,999$
(C) $\$ 100,000-\$ 149,999$
(C) $\$ 150,000-\$ 199,999$
(C) $\$ 200,000-\$ 249,999$
(C) $\$ 250,000$ and above

8. What is the highest level of education that you have completed?
Less than high school
High school graduate or equivalent (i.e. GED)
Some college, but no degree
Associate degree
B Bachelor's degree
6 Master's degree
Doctorate

9. Do you have a child/children under 18 years old in your household?
(r) Yes
(C) No

10. What type of water do you most often drink?

Bottled Water

(C) Tap Water

Filtered Tap Water 
11. Before this survey had you ever heard of:

Yes No

All Fresh Water
All Natural Water
$\begin{array}{ll}\text { Eco-Friendly Water } \\ \text { Pure Water }\end{array}$
Advanced Purified Water

12. What percentage of the U.S. drinking water supply do you think contains treated wastewater? Please give your best estimate.

13. What percentage of the drinking water you consume do you think contains treated wastewater? Please give your best estimate. 


\section{The Department of Applied Economics and Statistics \\ College of Agriculture and Natural Resources \\ University of Delaware}

The Department of Applied Economics and Statistics carries on an extensive and coordinated program of teaching, organized research, and public service in a wide variety of the following professional subject matter areas:

\section{Subject Matter Areas}

Agricultural Policy

Food and Agribusiness Management and Marketing

Natural Resource Management

Rural and Community Development
Environmental and Resource Economics International Agricultural Trade

Price and Demand Analysis

Statistical Analysis and Research Methods

The department's research in these areas is part of the organized research program of the Delaware Agricultural Experiment Station, College of Agriculture and Natural Resources. Much of the research is in cooperation with industry partners, the USDA, and other State and Federal agencies. The combination of teaching, research, and service provides an efficient, effective, and productive use of resources invested in higher education and service to the public. Emphasis in research is on solving practical problems important to various segments of the economy.

The mission and goals of our department are to provide quality education to undergraduate and graduate students, foster free exchange of ideas, and engage in scholarly and outreach activities that generate new knowledge capital that could help inform policy and business decisions in the public and private sectors of the society. APEC has a strong record and tradition of productive programs and personnel who are engaged in innovative teaching, cutting-edge social science research, and public service in a wide variety of professional areas. The areas of expertise include: agricultural policy; environmental and resource economics; food and agribusiness marketing and management; international agricultural trade; natural resource management; operations research and decision analysis; rural and community development; and statistical analysis and research methods. 
APEC Research

Reports are published

by the Department of

Applied Economics

and Statistics, College

of Agriculture and

Natural Resources of

the University of

Delaware.

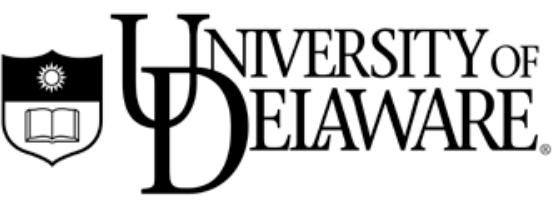

